\title{
Insulin love and care: psychological, social and economic determinants of type I diabetes care in India
}

Keywords: Half century of type 1, Insulin dependent, Childhood diabetes, Insulin love and care, not TB, Leprosy

\section{Introduction}

Half century of type 1 (Insulin dependent) childhood diabetes in India: change, progress and future? $(1970 \mathrm{~s}-2010 \mathrm{~s}){ }^{1}$

Till the 1970's, 'juvenile diabetes' (insulin dependent diabetes) was considered a rare disease in India; such children of poor families were often 'adopted' to live permanently (or for extended periods) in some government hospitals ['museum specimens' for medical students]. 'Death before diagnosis' was likely rampant, though unquantitated. Medical education among physicians was rudimentary, awareness among public was non-existent [add malnutrition and infectious diseases]. Government involvement was nil.

Since the last 50years major progressive steps in diagnosis, medical care and longevity of children in India is recorded. The reasons: 1. Global medical and technological advances 2. Dedicated, creative and socially relevant translational medicine and health care delivery programs, led by few committed individuals/ institutions [championed by Prof MMS Ahuja, Father of Indian Diabetology]. A few landmark projects are: 1. 1970s: Clinical, genetic and immunological characterization of type 1 diabetes in India [elucidating identity with the disease in the 'west' - India's first and largest series of 130 type 1 diabetes children] 2. 1980s: implementation of systematic patient health education and self-care training programs at clinic/ hospital [India's first - diabetes educator / nurse specialist, residential camps, foot nurse/podiatrist]. 3. Enrichment of medical education [UG/ PG level], continuing medical education of physicians at all levels 4.1990s: limited public philanthropy, free insulin and medical care via few grass roots organizations [supported also by industry], increasing number of physicians and other health professionals - manpower and skills development, 5. 2000s: significant drop in cost of insulin, due to local manufacture - competitive market, implementation of certified insulin pump therapy programs and CGM programs, 6. Government focus for diabetes care.

The recent apparent economic spurt of India, has contributed to improving the health care standards of the nation. However, disparity in wealth and health between the 'haves' and have nots' remains. [Eg: Use of world class insulin pump programs by affluent vs sheer unaffordability of cheapest form of insulin for majority on other hand]. Aggressive poverty alleviation coupled with higher priority assignment and focused commitment by the government and private sector for type 1 diabetes [in the total national health scenario], is necessary for securing future of the children and thereby the future of the country.

\section{Insulin love and care $^{2}$}

Beside physiological substitution of insulin, psychosocial care is probably the most important part of the management of diabetes in
Volume 4 Issue $6-2017$

Srikanta S, Kamala T, Chandraprabha S, Vasanti Nath, Pushpa Ravikumar, LakshmiV Reddy, Babitha Devi T, Reshma BV,Tejaswini Deepak, Kavitha M, Sumitra A, Muralidhar Krishna, Rajiv K, Sharda A, Chandrika KM, Sumathi K, Chitra MD, Nagamani Srinivas, Geetha Rao S, Dayashankar U, Rangaraj U,Vasanthalakshmi HK, Vibha Rao, Jayaram N, Ashok R, Hegde A, Manjunath R, Naik B, Chetana KL, Manjunath S, Vasantha Kumari, Rajiv K, Sunitha B, Amit Kumar Sinha

Samatvam Endocrinology Diabetes Center and Jnana Sanjeevini Diabetes Hospital and Medical Center, India

Correspondence: : Srikanta S, Samatvam Endocrinology Diabetes Center and Jnana Sanjeevini Diabetes Hospital and Medical Center, India,Email samatvam@gmail.com

Received: January 20, 2017 | Published: June 19, 2017

children and adolescents. [Horm Res. 1989, 31(5-6):204-9. Insulin, love and care. Ludvigsson J.] This is well known by every experienced clinician but very difficult to document scientifically. Traditional methods useful and necessary in clinical or experimental research are often rough and irrelevant in the description of complicated and 'soft' psychological phenomena, and statistical methods are of little help to prove whether the feelings of a child are acceptable or not. The psychological crisis of the child who gets diabetes and his/her family members, need utmost attention, both during the initial diagnosis [a life changing event for the entire family], and during the remainder of the life [with its numerous medical and non-medical challenges]. The attitudes and devotion of the numerous medical staff involved in the lifelong health care, as well as, the quality and systems of health care delivery in the society are most crucial.

Physical Poverty: Despite provision of enhanced material support [ie: insulin, syringes, tests], a subset of poverty - associated type 1 diabetes children, do not demonstrate improved glycemic control and overall health. ${ }^{3}$

Objectives: We have tried to identify the spectrum of glycemic control and overall clinical responses associated with the recent provision of significant material boost in a 3 decade long FREE Type 1 Diabetes Program in India.

Methods: Project DISHA - Insulin Lifeline: Beginning 1987, nearly 3000 children $[600+$ active] have been provided free insulin and syringes, since 2006, blood glucose meters and 5-10 strips/month were added. DISHA + CDiC / LFAC: 2011 - ongoing: [Changing Diabetes in Children [CDiC] and Life for a Child with Diabetes [LFAC]: Since 2011, 250 DISHA children are receiving significant 
material boost from the ongoing global CDiC / LFAC projects, which besides insulin and syringes, supports 100 BG strips per child per month, limited biochemical evaluations [baseline TSH, quarterly HbAlc testing, annual urine albumin: creatinine ratio], and limited manpower support [part time Diabetes Educator, Physician and
Ophthalmologist]. After 2 years of follow-up [2011-2013] of these children with the "CDiC/LFAC enhanced support", we could identify 4 major sub-groups, based on the patterns of response, in terms of improved glycemic control [ie., 3 monthly HbAlc assessments]:

\section{Results}

\begin{tabular}{lllll}
\hline Group & $\mathbf{n}[\%]$ & HbA I c baseline and trend & Baseline & Latest \\
\hline A: Prior Discipline Already Good & $17[1 \mathrm{II}]$ & $<8$ and stable & 7.3 & 7 \\
B: Responder High & $35[22]$ & $>8$ and $>3$ decline & 14.8 & 9.1 \\
C: Responder & $59[37]$ & $>8$ and 0.6 to 3 decline & 10.9 & 9.2 \\
D: Non- Responder Sad!! & $49[3 \mathrm{II}$ & $>8$ and $<0.6$ decline & 10.4 & 11.5 \\
\hline
\end{tabular}

Percent of children achieving HbAlc target <8[29\%], <7[I2\%]. Nephropathy \% [mean UAC $\mu$ g/mg of Creatinine]: Nil 58\% [I0], Incipient 29\% [88], Overt I3 \% [1073]. Primary hypothyroidism: Newly detected 13\%.

\section{Conclusion}

Despite provision of enhanced material support [ie: more blood glucose strips, periodic biochemical monitoring etc], a subset of poverty - associated type 1 diabetes children, do not demonstrate improved glycemic control and overall health. Most likely, varying combination of detrimental psychological, social and economic factors other coexisting life challenges, contribute to this "poorresponse" or "non-response" in a crowded pediatric diabetes clinic, in a resource limited settings

\section{Spiritual poverty}

In a reverse situation, a subset of affluent - affordable ["rich"] group of children, also face numerous challenges and difficulties with their type 1 diabetes. These challenges are predominantly psychosocial, and these youngsters also need consistent, lifelong and genuine love and care, from all concerned - family, society and the diabetes care team. Often, even insulin pumps, unlimited self home blood glucose monitoring, continuous glucose monitoring etc do not always ensure best glycemic control and quality of life in these children. ${ }^{4}$

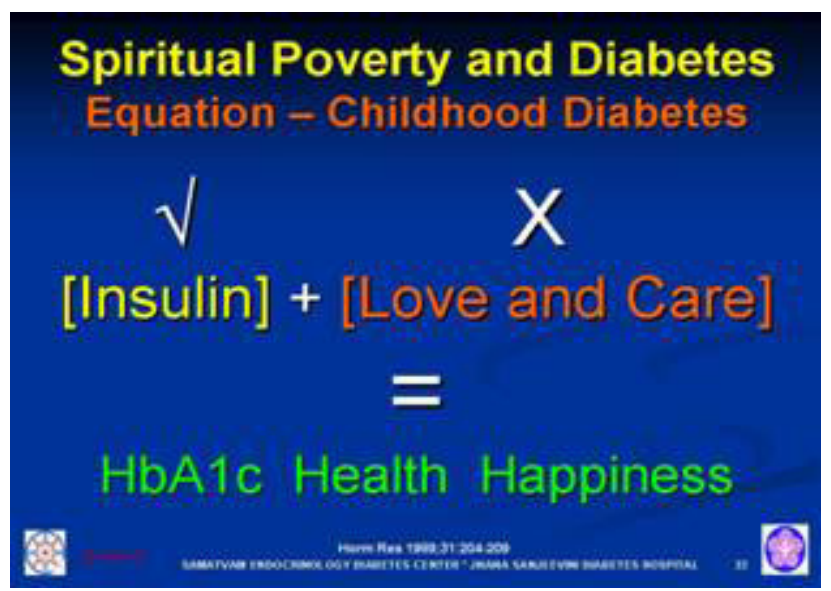

"The greatest disease in the West today is not TB or leprosy it is being unwanted, unloved, and uncared for. We can cure physical diseases with medicine, but the only cure for loneliness, despair, and hopelessness is love. There are many in the worlds that are dying for a piece of bread but there are many more dying for a little love. The poverty in the West is a different kind of poverty -- it is not only poverty of loneliness but also of spirituality. There's a hunger for love, as there is a hunger for God." -Mother Teresa, A Simple Path: Mother Teresa. $^{5}$

\section{Intervention- therapy}

In both the above groups, in depth analysis and identification of these negative therapeutic factors, and sincere efforts to mitigate the same ["molecular sociology" and psychosocial therapy, High risk type 1 diabetes clinics], are crucial to ensure the short and long term health and survival of these children, as well as, peace, tranquility and harmony of the family. The long term sustenance of such programs, and support to newly arriving children remains a big challenge.

After centuries of conquest and colonisations, the independent India, has struggled towards economic progress, social equity and overall improvement in quality and quantity of life for all its citizens, Thus, the collective goal of all diabetes health care professionals must be to develop a holistic "care model" [for both poor and rich], that improves long term glycemic control and overall health and wellbeing of children, youth and young adults with type 1 diabetes, and their family members, in India and world over.

\section{Acknowledgments}

None.

\section{Conflicts of interest}

The authors declare that there are no conflicts of interest.

\section{References}

1. Vidula Krishnaswamy, Srikanta S. Half century of type 1 (insulin dependent) childhood diabetes in India: Change, progress and future? (1970s-2010s). Abstract number: ME-1912: Presented at the World Diabetes Congress 2013 Melbourne. International Diabetes Federation, Melbourne, Australia. 2013.

2. Ludvigsson J. Insulin, love and care. Horm Res. 1983;31(5-6):204-209.

3. Uma Dayashankar, Srikanta S. Insulin, love and care: Poor response subset in a have-not type 1 diabetes clinic [DISHA] in India. Abstract A-664-0013-00187. Oral presentation at $40^{\text {th }}$ Annual Conference of the International Society for Pediatric and Adolescent Diabetes, Toronto, Canada. 2014.

4. Srikanta S. Childhood Diabetes and Poverty: Limitation of which resource? Physical, spiritual or both? Oral presentation: Conference of IDF Life for a Child with Diabetes, Chicago, USA. 2013.

5. Mother Teresa. A simple path. Ballantine Books: New York, USA. 1995. 